\title{
Fitness of Botrytis cinerea Associated with Dicarboximide Resistance
}

\author{
R. Raposo, V. Gomez, T. Urrutia, and P. Melgarejo
}

First and fourth authors: Department of Plant Protection, CIT-INIA, Ca. Coruña km 7, 28040 Madrid, Spain; and second and third authors: Department of Vegetable Protection, 04004 Almeria, Spain.

Accepted for publication 24 July 2000.

\begin{abstract}
Raposo, R., Gomez, V., Urrutia, T., and Melgarejo, P. 2000. Fitness of Botrytis cinerea associated with dicarboximide resistance. Phytopathology $90: 1246-1249$.

Fitness costs in Botrytis cinerea associated with dicarboximide resistance were studied. Spearman rank correlation coefficients were calculated between resistance to iprodione and survival ability both outside and inside the greenhouse, measured on isolates randomly chosen from a collection done in a survey of commercial greenhouses in Southeastern Spain in 1992. Survival was measured at 47, 83, and 110 days as

percentage of surviving mycelia in a sample of artificially inoculated tomato stem pieces and as percentage of viable sclerotia from a sample of sclerotia produced on potato dextrose agar. Resistance to iprodione was measured by the fungicide concentration that reduces fungal growth by $50 \%\left(\mathrm{EC}_{50}\right.$ values). Significant $(P<0.05)$ negative correlation coefficients between survival of sclerotia and resistance to iprodione were found for some samplings dates, which indicates that sclerotia of resistant isolates survive less well than sclerotia from sensitive isolates. For mycelia, no relationship between survival and resistance was found.
\end{abstract}

Fitness of pathogen isolates resistant to fungicides is an important consideration in disease management. If fitness costs are associated with fungicide resistance, the frequency of resistant isolates will decline in the absence of the fungicide. Furthermore, mixtures or alternations with fungicides of different modes of action could be instituted to delay the selection for fungicide resistance $(2-4,14,21)$. Alternations are more effective than mixtures if fitness costs are associated with resistance to each fungicide used in the alternation $(3,14)$.

Fitness costs in Botrytis cinerea Pers ex Fr., associated with dicarboximide resistance is widely accepted $(2,14,20,21)$. There is some evidence of a decline in resistance frequencies in the field when use of dicarboximides is discontinued. For example, in the Champagne region in France, percentage of resistance decreased from 90 to below $20 \%$ in 6 years, after treatments with dicarboximides were officially discontinued to control $B$. cinerea in grapes (20). However, immigration of sensitive isolates or genetic drift could also have been involved in these observations.

There are several experimental studies that evaluate the relationship between fitness and fungicide resistance, but results are quite contradictory $(5,6,9,10,13,16)$. In the case of dicarboximideresistant isolates of $B$. cinerea, multiple resistance to benzimidazole and dicarboximide in $B$. cinerea was associated with reduced sporulation (5), although other researchers found no differences in fungicide-sensitive phenotypes in the area under disease progress curve; in linear growth rates (10) or in lesion growth rates and sporulation (16). Attributes such as these mentioned, which are measured in a single reproductive cycle, define the predicted fitness (1). Therefore, results support either a reduced or a similar parasitic fitness of dicarboximide-resistant isolates of $B$. cinerea. As pointed out by Peever and Milgroom (13), possible reasons for the contradictions found in the literature are that these studies

Corresponding author: P. Melgarejo; E-mail address: melgar@inia.es

Publication no. P-2000-0911-03R

(C) 2000 The American Phytopathological involved a few isolates possibly from different populations, and fitness differences between resistant and sensitive isolates may have been due to differences in the genetic background of the isolates rather than fitness costs.

Recently, a procedure to measure correlations between fitness and resistance to fungicides has been described $(12,13)$. This method describes procedures to separate genetic and environmental factors controlling resistance and fitness components and methods to estimate the genetic and phenotypic correlations between them. According to this method, the lack of correlation between fitness and dicarboximide resistance in $B$. cinerea isolates from Spanish greenhouses has been demonstrated (16). In that study, the components of fitness measured on inoculated cucumber leaves were lesion growth rate and sporulation, characteristics related to the parasitic cycle of the pathogen. However, other attributes related to the nonpathogenic phase such as the ability to overseason were not considered and may be correlated with the dicarboximide resistance.

In this paper we study the relationship between fitness and resistance to dicarboximides in $B$. cinerea. We calculated the correlation between surviving ability and dicarboximide-resistance phenotypes measured on isolates collected from commercial greenhouses located in Southeast Spain. This region is of intensive production of vegetables (cucumber, bean, tomato, pepper, eggplant, and squash) in unheated plastic greenhouses, where $B$. cinerea attacks almost every year causing Gray mold disease. Fungicides, including dicarboximides, are applied commonly in alternations in a regular schedule to control the disease. In a survey of B. cinerea carried out in Southeast Spain in 1992 (16), $28 \%$ of 261 isolates sampled were sensitive to both benzimidazoles and dicarboximides, $46 \%$ were resistant to both fungicides, $15 \%$ were benzimidazole-resistant, and $8 \%$ were dicarboximide-resistant. Unlike Northern Europe, B. cinerea usually attacks this region in winter and it survives in summer under a regime of high temperature (especially inside greenhouses) and scarce precipitation. $B$. cinerea survives as sclerotia and as mycelium growing on plant debris in the soil (17). We measured the surviving ability of sclerotia and mycelia on tomato stem fragments under field conditions and calculated their correlation with dicarboximide sensitivity. 


\section{MATERIALS AND METHODS}

Isolates of $\boldsymbol{B}$. cinerea. Isolates were collected in a survey carried out in December 1992 in commercial greenhouses located in the southeast region of Spain. Isolates were maintained in sand with oatmeal $(3 \%, \mathrm{vol} / \mathrm{vol})$ at $4{ }^{\circ} \mathrm{C}$. Isolates were arbitrarily chosen from this collection and grown on potato dextrose agar (PDA) at $22^{\circ} \mathrm{C}$ in the dark for production of mycelium. Different isolates were used each year.

Survival under field conditions. Survival of mycelia and sclerotia was quantified in the summers of 1995 and 1997. Two experiments were carried out in one polyethylene greenhouse each year located at the Experimental Station of Vegetable Crops in Almeria, Spain. Survival of mycelia was studied on tomato stem fragments artificially inoculated with 10 isolates in 1995 (six isolates were dicarboximide-resistant and four isolates were sensitive), and with seven different isolates in 1997 (five isolates were dicarboximide-resistant and two isolates were sensitive). To produce the stem fragments, tomato plants (cv. Lorena) were grown in pots until they had five to seven leaves. Tomato stems of 2- to 6-mm in diameter were cut into $2-\mathrm{cm}$ pieces and inoculated by immersion in a spore suspension of $B$. cinerea. The stem fragments were incubated in petri dishes with wet sterile filter paper in a chamber at $22^{\circ} \mathrm{C}$. After the pieces showed (5 to 7 days) symptoms of $B$. cinerea infection, they were dried at $30^{\circ} \mathrm{C}$ for 7 days and placed in four nylon bags of $0.3-\mathrm{mm}$ mesh. To study survival of sclerotia, 12 isolates in 1995 (eight were dicarboximide-resistant and four were sensitive), and 11 isolates in 1997 (seven were resistant and four were sensitive) were randomly chosen. Sclerotia were obtained from PDA (Oxoid, London) petri dishes $(9 \mathrm{~cm})$ after incubating them in the dark at $20^{\circ} \mathrm{C}$ for 17 days. Sclerotia were harvested with forceps, stirred in Tween 80 solution $(1 \%)$ for $30 \mathrm{~min}$, and rinsed twice in sterile water. They were dried on the lab bench and stored there until used. Four bags per isolate were placed on the soil surface inside (two bags) and outside (two bags) the greenhouse, and a hygrothermograph was placed at $1 \mathrm{~m}$ to record temperature and relative humidity. Bags were set on 1 June 1995 and on 17 June 1997. They were near a lateral border inside the greenhouse, and outside between two greenhouses.

To measure survival of mycelium on tomato stems and sclerotia over time, samplings of 10 stem pieces and 10 sclerotia from each bag were randomly taken at 47, 71, and 106 days in 1995 and 1997. Survival was evaluated on stem pieces and on sclerotia at time 0 , that is, before bags were laid out. Stem fragments and sclerotia were surface sterilized by dipping them in a $1 \% \mathrm{NaOCl}$ solution for $1 \mathrm{~min}$ and rinsed twice in sterile-distilled water. After they were dried on sterile filter paper, each stem piece (previously split lengthwise) and sclerotium was placed on PDA with streptomycin $(500 \mathrm{mg} / \mathrm{liter})$ and incubated in the dark at $22^{\circ} \mathrm{C}$. Survival was evaluated by the presence of Botrytis hyphal growth on PDA in 6 days and by pathogenicity assays. Pathogenicity tests were done on cucumber cotyledons (cv. Hyclos Mix F1 RS; Ramiro Arnedo SA, La Rioja, Spain), detached and placed in petri dishes on two filter papers soaked with sterile-distilled water. Cotyledons were inoculated with 4-mm diameter plugs of actively growing mycelium and incubated at $22^{\circ} \mathrm{C}$ in the dark for 6 days. Isolates were considered pathogenic if cotyledons were soft rotted.

Data were given as the proportion of viable (i.e., surviving and pathogenic) mycelium on stem pieces and viable sclerotia over a sample of 10 . For each sampling date, there were two replications per isolate inside and outside the greenhouse. All data were referred to viability at time 0 .

Fungicide sensitivity. The fungicide concentration of iprodione (used as technical grade; Rhône-Poulenc Agro SA, Madrid, Spain) that reduced fungal growth by $50 \%$ ( $\mathrm{EC}_{50}$ value) was determined for each of the isolates used in the field experiments. An auto- mated quantitative method was applied as described previously (15) to establish the dose-response curves. Isolates were grown in potato dextrose broth (Difco Laboratories, Detroit) in the wells of a microplate with different fungicide concentrations. After $46 \mathrm{~h}$ of incubation at $20^{\circ} \mathrm{C}$ in darkness, fungal growth was determined by measuring absorbance at $492 \mathrm{~nm}$. Wells of microplates contained 1,000 conidia in a final volume of $100 \mu \mathrm{l}$. Conidia were obtained from PDA inoculated as usual and grown in a growth chamber for 7 days (16-h photoperiod; $25^{\circ} \mathrm{C}$ under fluorescent light and $21^{\circ} \mathrm{C}$ in the dark). Conidia were stored at $-20^{\circ} \mathrm{C}$ in a $20 \%$ glycerol solution until needed. All $\mathrm{EC}_{50}$ values were determined two to four times and their mean and standard error calculated.

Data analysis. Percent viability of mycelia and sclerotia was analyzed for each sampling date. Analysis of variance (ANOVA) was performed with the general linear models procedure (GLM) of SAS (Statistical Analysis System, version 6; SAS Institute Inc., Cary, NC) with the following factors considered in the model: year of the experiment (1995 and 1997), location of the bags (inside and outside the greenhouse), and isolates as a random factor nested in 'year' factor. 'Isolates' was considered a random factor because different isolates were used each year of the experiment. In order to have the same number of isolates each year of the experiment for the ANOVA, 3 isolates out of 10 and 1 isolate out of 12 were randomly dropped from the 1995 data for mycelia and sclerotia survival, respectively. Percent survival data were transformed to arc sin of square root of the proportion prior to the ANOVA. Appropriate $F$ tests for each term of the model were derived from the expected mean squares, which were obtained by application of the rule for finding expected mean squares (11). From expected mean squares, the variance among isolates was estimated (19), and the two variance components (among isolates and error) were expressed as percentages of the sum of their variances (19).

To study the association between the percentage of survival and the dicarboximide sensitivity $\left(\mathrm{EC}_{50}\right.$ values), the Spearman rank correlation coefficient was used. This is a nonparametric method and it does not require the condition of normality of the variables to test for the significance of the association (19). In our case, neither the percentage of survival nor the fungicide sensitivity were normally distributed. The rank correlation coefficient of Spearman was calculated over years for each sampling date in each location (outside or inside the greenhouse) and appropriate tables were used for significance testing (18). The total number of isolates used in this study was 17 for mycelia survival (10 in 1995 and 7 in 1997) and 23 for sclerotia (12 in 1995 and 11 in 1997).

\section{RESULTS}

Survival under field conditions. Viability of sclerotia was greater outside than inside the greenhouse each year of the experiment (Table 1). In 1995, viability outside the greenhouse remained $\approx 90 \%$ for almost all the isolates in the experiment, and only three isolates had decreased viability at day 83 . In 1997, survival of the isolates located outside the greenhouse varied in their response after 47 and 83 days; some isolates scarcely decreased in viability whereas others did decrease. After 110 days of exposure, the survival of all isolates decreased sharply. Viability inside the greenhouse rapidly decreased in 1995. At day 83 only three isolates were viable, and at day 110 only one isolate. On the contrary, in 1997 only three isolates completely lost their viability after 110 days of exposure. All recovered sclerotia were pathogenic.

Viability of mycelia showed a wide variability outside the greenhouse. Some isolates were not viable at day 110 in 1995 , whereas others were at $80 \%$. In 1997, 3 of 11 isolates tested were less viable outside than inside the greenhouse. Viability of all the isolates tested decreased rapidly at day 47 inside the greenhouse in both years of the experiments and viability was near 0 on the other sampling dates. Recovered mycelia were always pathogenic. 
Survival of sclerotia and mycelia was significantly different among isolates for all samplings dates except for survival of mycelia on the second sampling date (Tables 2 and 3).

Fungicide sensitivity. Dicarboximide sensitivity of the isolates was in two ranges, one for the sensitive and another one for the resistant isolates. In 1995, three isolates were resistant $\left(\mathrm{EC}_{50}\right.$ values in the range of 1.58 to $3.01 \mathrm{mg} /$ liter of iprodione) and four were sensitive ( 0.36 to $0.49 \mathrm{mg} /$ liter of iprodione). In 1997 , five isolates were resistant ( 1.58 to $2.7 \mathrm{mg} / \mathrm{liter}$ of iprodione) and two were sensitive $(0.40$ and $0.49 \mathrm{mg} /$ liter of iprodione). For the sclerotia assay, seven isolates were resistant $(1.58$ to $3.01 \mathrm{mg} / \mathrm{liter}$ of iprodione) and four were sensitive ( 0.36 to $0.49 \mathrm{mg} / \mathrm{liter}$ of iprodione) in each year.

Correlations between fitness and resistance. Coefficients of association between resistance to iprodione and survival of sclerotia and mycelia were estimated outside and inside the greenhouse for each sampling date (Table 4). A significant negative relationship $(P<0.05)$ was found between percentage of survival of sclerotia after 83 days of exposure outside the greenhouse. A significant negative association was also found between survival of sclerotia inside the greenhouse after 47 days. Survival of mycelia either outside or inside the greenhouse was not correlated to

TABLE 1. Percentage of survival of mycelia and sclerotia of Botrytis cinerea on the soil surface outside and inside the greenhouse after 47, 83, and 110 days of exposure ${ }^{\mathrm{a}}$

\begin{tabular}{|c|c|c|c|c|c|c|c|}
\hline \multirow[b]{2}{*}{ Structure $^{\mathrm{b}}$} & \multirow[b]{2}{*}{ Location } & \multicolumn{3}{|c|}{1995} & \multicolumn{3}{|c|}{1997} \\
\hline & & 47 & 83 & 110 & 47 & 83 & 110 \\
\hline \multirow[t]{2}{*}{ Sclerotia } & Outside & $\begin{array}{l}92.2 \\
(1.1)\end{array}$ & $\begin{array}{c}88.1 \\
(2.3)\end{array}$ & $\begin{array}{c}91.3 \\
(1.2)\end{array}$ & $\begin{array}{c}81.6 \\
(1.5)\end{array}$ & $\begin{array}{c}75.5 \\
(1.9)\end{array}$ & $\begin{array}{c}38.5 \\
(2.3)\end{array}$ \\
\hline & Inside & $\begin{array}{l}31.2 \\
(3.1)\end{array}$ & $\begin{array}{c}8.9 \\
(2.2)\end{array}$ & $\begin{array}{c}0.9 \\
(0.2)\end{array}$ & $\begin{array}{c}46.4 \\
(1.8)\end{array}$ & $\begin{array}{c}32.6 \\
(1.5)\end{array}$ & $\begin{array}{l}14.9 \\
(1.3)\end{array}$ \\
\hline \multirow[t]{2}{*}{ Mycelia } & Outside & $\begin{array}{l}57.4 \\
(2.4)\end{array}$ & $\begin{array}{c}44.8 \\
(2.6)\end{array}$ & $\begin{array}{c}32.5 \\
(2.8)\end{array}$ & $\begin{array}{c}26.4 \\
(3.0)\end{array}$ & $\begin{array}{l}12.2 \\
(1.5)\end{array}$ & $\begin{array}{c}5.1 \\
(1.3)\end{array}$ \\
\hline & Inside & $\begin{array}{c}7.1 \\
(1.2)\end{array}$ & $\begin{array}{c}2.3 \\
(0.3)\end{array}$ & $\begin{array}{c}0 \\
(0)\end{array}$ & $\begin{array}{l}14.1 \\
(1.6)\end{array}$ & $\begin{array}{c}6.3 \\
(1.1)\end{array}$ & $\begin{array}{c}7.4 \\
(1.2)\end{array}$ \\
\hline
\end{tabular}

a Data are mean percentages of viable mycelium on tomato pieces and of sclerotia over a sample of 10 . Standard errors are in parentheses.

${ }^{b}$ Survival of mycelia was tested on artificially inoculated stem pieces of tomato. Pieces were inoculated with seven isolates each year. Sclerotia were produced on potato dextrose agar, and 11 isolates were used each year. Each isolate was repeated twice. resistance to dicarboximide. All significant coefficients were negative, meaning that resistant isolates (high $\mathrm{EC}_{50}$ values) survived less time (small percentage value).

\section{DISCUSSION}

The relationship between resistance to dicarboximides and fitness was investigated. Fitness was evaluated by the ability of the isolates to survive as mycelia in plant debris and sclerotia on the soil in summer. Our results show that sclerotia of dicarboximidesensitive isolates survive better than resistant ones. This was found when sclerotia were exposed for 47 days inside the greenhouse and for 83 days outside the greenhouse. On the contrary, survival of mycelia of $B$. cinerea in tomato stem pieces was not correlated to dicarboximide resistance.

TABLE 4. Rank correlation coefficients between resistance to iprodione (dicarboximide fungicide) and survival ability of mycelia and sclerotia of Botrytis cinerea located outside and inside the greenhouses ${ }^{\mathrm{a}}$

\begin{tabular}{lccccc}
\hline & \multicolumn{2}{c}{ Mycelia } & & \multicolumn{2}{c}{ Sclerotia } \\
\cline { 2 - 3 } \cline { 5 - 6 } Sampling date & Outside & Inside & & Outside & Inside \\
\hline \multirow{2}{*}{47 days } & 0.062 & 0.062 & & -0.169 & $-0.435^{*}$ \\
& $(0.806)$ & $(0.806)$ & & $(0.429)$ & $(0.041)$ \\
83 days & -0.290 & -0.262 & & $-0.592^{*}$ & -0.303 \\
& $(0.247)$ & $(0.294)$ & & $(0.006)$ & $(0.155)$ \\
\multirow{2}{*}{110 days } & 0.012 & 0.099 & & -0.150 & -0.315 \\
& $(0.961)$ & $(0.692)$ & & $(0.483)$ & $(0.139)$ \\
\hline
\end{tabular}

a Sample size is 17 and 23 isolates for mycelia and sclerotia coefficient values, respectively. $P$ value for the null hypothesis in parentheses. Numbers followed by an asterisk are coefficients significantly different from 0 .

TABLE 5. Relative proportions (in percentage) of the error and genetic variances out of the total variation among isolates in survival of mycelia and sclerotia of Botrytis cinerea sampled at different times ${ }^{\mathrm{a}}$

\begin{tabular}{llccc}
\hline Structure & Variance & 47 days & 83 days & 110 days \\
\hline Mycelia & Genetic & 29.4 & 2.7 & 35.6 \\
& Error & 70.6 & 97.3 & 64.4 \\
Sclerotia & Genetic & 48.4 & 59.4 & 49.6 \\
& Error & 51.6 & 40.6 & 50.4 \\
\hline
\end{tabular}

a Total variation among isolates was obtained from the respective analysis of variance, and the relative proportions were derived from the expression of the expected mean square.

TABLE 2. Analysis of variance on percentage of survival of sclerotia of Botrytis cinerea for each sampling date ${ }^{\mathrm{a}}$

\begin{tabular}{|c|c|c|c|c|c|c|c|}
\hline \multirow[b]{2}{*}{ Source } & \multirow[b]{2}{*}{ df } & \multicolumn{2}{|c|}{47 days } & \multicolumn{2}{|c|}{83 days } & \multicolumn{2}{|c|}{110 days } \\
\hline & & MSE & $F$ value & MSE & $F$ value & MSE & $F$ value \\
\hline Location & 1 & $33,253.6$ & $56.99 *$ & $50,913.5$ & $99.62 *$ & $46,826.16$ & $213.4^{*}$ \\
\hline Year & 1 & 26.10 & 0.03 & $1,794.69$ & 1.75 & $3,743.93$ & $6.51 *$ \\
\hline Isolates (year) ${ }^{b}$ & 20 & 950.0 & $4.75^{*}$ & $1,023.60$ & $6.86^{*}$ & 575.53 & $4.94 *$ \\
\hline Location* year & 1 & $3,423.86$ & $5.87 *$ & $6,042.59$ & $11.82 *$ & $19,284.88$ & $87.86^{*}$ \\
\hline Location* isolate & 20 & 583.41 & $2.92 *$ & 511.05 & $3.43^{*}$ & 219.48 & $1.88^{*}$ \\
\hline Error & 44 & 199.9 & $\ldots$ & 149.21 & $\ldots$ & 116.46 & $\ldots$ \\
\hline
\end{tabular}

a * Statistical significance $(\alpha=0.05)$ of the respective mean square error (MSE) ratio $(F)$.

b Factor 'isolates' is nested in year because different isolates were used each year.

TABLE 3. Analysis of variance on percentage of survival of mycelia of Botrytis cinerea for each sampling date ${ }^{a}$

\begin{tabular}{|c|c|c|c|c|c|c|c|}
\hline \multirow[b]{2}{*}{ Source } & \multirow[b]{2}{*}{ df } & \multicolumn{2}{|c|}{47 days } & \multicolumn{2}{|c|}{83 days } & \multicolumn{2}{|c|}{110 days } \\
\hline & & MSE & $F$ value & MSE & $F$ value & MSE & $F$ value \\
\hline Location & 1 & $9,538.41$ & $24.74 *$ & $6,431.91$ & $26.89 *$ & $2,950.20$ & $13.09 *$ \\
\hline Year & 1 & 668.32 & 1.19 & $1,439.25$ & 3.59 & 786.46 & 2.41 \\
\hline Isolates (year) ${ }^{b}$ & 12 & 560.80 & $2.66^{*}$ & 400.49 & 1.11 & 326.17 & $3.21 *$ \\
\hline Location* year & 1 & $4,108.67$ & $10.66^{*}$ & $2,697.94$ & $11.28 *$ & $4,365.15$ & $19.36^{*}$ \\
\hline Location* isolate & 12 & 385.56 & 1.83 & 239.16 & 0.66 & 225.42 & $2.22 *$ \\
\hline Error & 28 & 210.45 & $\ldots$ & 360.19 & $\ldots$ & 101.61 & $\ldots$ \\
\hline
\end{tabular}

a * Statistical significance $(\alpha=0.05)$ of the respective mean square error (MSE) ratio $(F)$.

b Factor 'isolates' is nested in year because different isolates were used each year. 
Although fitness costs have been frequently associated with fungicide resistance, only one recent study (13) has shown the lack of correlation between fitness and resistance to sterol biosynthesis-inhibiting fungicides in Pyrenophora teres. An apparent decline in frequency of resistant isolates following discontinuation of dicarboximide applications in vineyards has provided anecdotal evidence that dicarboximide-resistant isolates are less fit than wild-type strains (20), but other factors such as immigration and genetic drift could also explain such observations. However, our results indicate that differences in survival of $B$. cinerea do correlate with resistance to dicarboximide. Many traits are involved in the organisms contribution to a subsequent generation (components of fitness), but only studies based on the components related to the pathogenic phase of $B$. cinerea (lesion growth and sporulation) have been evaluated in their correlation to resistance to dicarboximides (16). Differences in survival of metalaxyl resistant and sensitive isolates are found in Phytophthora infestans, and metalaxyl sensitive isolates survived in infected potato tubers better than the resistant isolates (7). Our results may support those observations reported previously in Israel (8), a Mediterranean country with similar conditions to those described here. In those conditions, no dicarboximideresistant isolates of $B$. cinerea were detected in primary infections or in airborne inoculum early in the season.

Results presented here are based on the mean response for each variable (percentage of survival and $\mathrm{EC}_{50}$ values of iprodione). Survival of sclerotia (Table 2) and mycelia (Table 3) was significantly different among isolates for all samplings days except for survival of mycelia on the second sampling date. These results imply the existence of a variance among isolates in addition to the error variance, variance that is likely due to genetic differences in isolates. Therefore, our results indicate that there were genetic differences in isolates that contributed to variation on survival either as sclerotia or as mycelia. These results did not apply for survival of mycelia after 83 days of exposure, in which the contribution of the error variance to the total variation among isolates was $97 \%$ (Table 5). Although genetic variation of isolates in surviving ability of sclerotia and mycelia was estimated, it was not possible to establish genetic correlations between resistance and fitness. In order to do this, it is necessary to partition the variance of both variables and the covariance between them into their genetic and environmental components; it was not possible to partition out the covariance, because the same number of repetitions in the experiment was needed. Correlation coefficients between fitness and resistance obtained by the mean response for each variable closely approximates the correlation coefficient obtained by genetic correlations (13).

Survival of mycelia of $B$. cinerea and resistance were not correlated when isolates were exposed to either outside or inside greenhouse conditions. Response of mycelia to environmental conditions is quite variable, as seen from the high contribution of the error variance to the total variance among isolates (Table 5). The error variance is due to differences in experimental and environmental responses and is considered an estimation of the environmental variance. The higher error variance together with a smaller sample size (mean response of 17 isolates for mycelia survival compared with 23 isolates for sclerotia survival) may explain the wide range obtained for the rank correlation coefficient calculated for survival of mycelia and resistance to iprodione $(-0.290$ to 0.099$)$ and the lack of correlation obtained for them.

Implications for disease management are important in the greenhouses of Southeastern Spain and the Mediterranean area. Most of the primary inocula is of dicarboximide-sensitive isolates, so an appropriate fungicide regime that takes this into account could be defined. Relative importance of sclerotia and mycelia as sources of primary inocula need to be quantified.

\section{ACKNOWLEDGMENTS}

This research was supported by INIA project SC97-059 and FIAPA project 97/B3/146. We thank C. Simón, M. D. Alferez-Garcia, and M. M. Martinez-Narvaez for their technical assistance.

\section{LITERATURE CITED}

1. Antonovics, J., and Alexander, H. M. 1988. The concept of fitness in plant-fungal pathogen systems. Pages 185-214 in: Plant Disease Epidemiology. Vol. 2. K. J. Leonard and W. E. Fry, eds. McGraw-Hill Publishing Co., New York.

2. Brent, K. J. 1995. Fungicide resistance in crop pathogens: How can it be managed? Fungicide Resistance Action Committee monograph No. 1. Groupment Int. Assoc. Nat. Fabricants Prodvits Agrochemiques, Brussels.

3. Dekker, J. 1982. Can we estimate the fungicide-resistance hazard in the field from laboratory and greenhouse tests? Pages 128-139 in: Fungicide Resistance in Crop Protection. J. Dekker and S. G. Georgopoulos, eds. Cent. Agric. Publ. Doc., Wageningen, the Netherlands.

4. Fry, W. E., and Milgroom, M. G. 1990. Population biology and management of fungicide resistance. Pages 275-285 in: Managing Resistance to Agrochemicals: From Fundamental Research to Practical Strategies. M. B. Green, W. K. Moberg, and H. LeBaron, eds. Am. Chem. Soc. Symp. Ser. No. 421

5. Hsiang, T., and Chastagner, G. A. 1991. Growth and virulence of fungicide-resistant isolates of three species of Botrytis. Can. J. Plant Pathol. 13:226-231.

6. Kadish, D., and Cohen, Y. 1988. Fitness of Phytophthora infestans isolates from metalaxyl-sensitive and -resistant populations. Phytopathology 78:912-915.

7. Kadish, D., and Cohen, Y. 1992. Overseasoning of metalaxyl-sensitive and metalaxyl-resistant isolates of Phytophthora infestans in potato tubers. Phytopathology 82:887-889.

8. Katan, T., and Ovadia, S. 1985. Effect of chlorothalonil on resistance of Botrytis cinerea to dicarboximides in cucumber glasshouses. Eur. Mediterr. Plant Prot. Organ. Bull. 15:365-369.

9. Mérida, C. L., and Loria, R. 1994. Comparison of thiabendazole-sensitive and -resistant Helminthosporium solani isolates from New York. Plant Dis. 78:187-192.

10. Moorman, G. W., and Lease, R. J. 1992. Benzimidazole- and dicarboximide-resistant Botrytis cinerea from Pennsylvania greenhouses. Plant Dis. 76:477-480.

11. Neter, J., Wasserman, W., and Kutner, M. H. 1985. Applied Linear Statistical Methods. 2nd ed. Richard D. Irwin, Homewood, IL.

12. Peever, T. L., and Milgroom, M. G. 1993. Genetic correlations in resistance to sterol biosynthesis-inhibiting fungicides in Pyrenophora teres. Phytopathology 83:1076-1082.

13. Peever, T. L., and Milgroom, M. G. 1994. Lack of correlation between fitness and resistance to sterol biosynthesis-inhibiting fungicides in $P y$ renophora teres. Phytopathology 84:515-519.

14. Peever, T. L., and Milgroom, M. G. 1995. Fungicide resistance: Lessons for herbicide resistance management. Weed Technol. 9:840-849.

15. Raposo, R., Colgan, R., Delcan, J., and Melgarejo, P. 1995. Application of an automated quantitative method to determine fungicide resistance in Botrytis cinerea. Plant Dis. 79:294-296.

16. Raposo, R., Delcan, J., Gomez, V., and Melgarejo, P. 1996. Distribution and fitness of isolates of Botrytis cinerea with multiple fungicide resistance in Spanish greenhouses. Plant Pathol. 45:497-505.

17. Smith, I. M., Dunez, J., Lelliott, R. A., Phillips, D. H., and Archer, S. A. (eds.). 1988. European Handbook of Plant Diseases. Blackwell Scientific Publications, Oxford.

18. Snedecor, G. W., and Cochran, W. G. 1980. Statistical Methods. 7th ed. Iowa State University Press, Ames.

19. Sokal, R. R., and Rohlf, F. J. 1981. Biometry. W. H. Freeman \& Co., San Francisco.

20. Staub, T. 1991. Fungicide resistance: Practical experience with antiresistance strategies and the role of integrated use. Annu. Rev. Phytopathol. 29:421-442.

21. Staub, T., and Sozzi, D. 1984. Fungicide resistance: A continuing challenge. Plant Dis. 68:1026-1031. 